\title{
Funding model and creativity in science: Competitive versus block funding and status contingency effects
}

\author{
Jian Wang (j.wang@sbb.leidenuniv.nl), Leiden University and DZHW Berlin \\ You-Na Lee (youna.lee@ nus.edu.sg), National University of Singapore \\ John P. Walsh* (jpwalsh@gatech.edu), Georgia Institute of Technology
}

December 9, 2017

*Corresponding author

Acknowledgements: We thank the Competence Center for Bibliometrics for the German Science System (KB) for access to their Web of Science database. The novelty measure is constructed from a database derived from the 1980 to 2012 Science Citation Index Expanded (SCI-E), Social Sciences Citation Index (SSCI), Arts and Humanities Citation Index (AHCI), Conference Proceedings Citation Index-Science (CPCI-S), and Conference Proceedings Citation Index-Social Science \& Humanities (CPCI-SSH) prepared by Thomson Reuters Inc. (TR®), Philadelphia, PA, USA: CCopyright Thomson Reuters 2013. KB is funded by the German Federal Ministry of Education and Research (BMBF, project number: 01PQ08004A). The survey data were collected with funding from Hitotsubashi University and Japan's National Institute for Science and Technology Policy. We thank Sadao Nagaoka and Masatsura Igami for sharing the Japanese survey data. J. Wang was partially supported by a postdoctoral fellowship from the Research Foundation - Flanders (FWO). J.P. Walsh and Y.-N. Lee were partially supported by a Georgia Tech Ivan Allen College research grant and by NSF grants (\#1262418 and \#1646689). Y.-N. Lee also acknowledges the support by Startup Grant (R-603-000-261-133) jointly from Ministry of Education, Singapore and Lee Kuan Yew School of Public Policy, National University of Singapore.

Jian Wang, You-Na Lee \& John P. Walsh (2018). Funding model and creativity in science: Competitive versus block funding and status contingency effects. Research Policy, 47(6), 10701083. https://doi.org/10.1016/j.respol.2018.03.014

(C) 2018 Elsevier B.V. All rights reserved. 


\begin{abstract}
In many countries the scientific funding system is shifting from an internal block funding model toward a competitive project funding one. However, there is growing concern that the competitive project funding system favors relatively safe, conventional projects at the expense of risky, novel research. It is important to assess different funding models in order to design better funding systems for science. This paper empirically tests for differences in the novelty of funded outputs between internal block funding and competitive project funding, in the setting of Japan, where both funding models play a significant role. Combining survey data from a large sample of research projects in Japan and bibliometric information about the publications produced from these projects, we find that projects funded by competitive funds on average have higher novelty compared to those funded by internal block funds. However, such positive effects only hold for researchers with high status, such as senior and male researchers. In contrast, compared to internal block funding, competitive project funding has a negative relation to novelty for low status scientists (especially junior and female researchers). The findings suggest that the competitive project selection procedure is less receptive to novel ideas from researchers with low academic status and therefore discourages their novel research. These findings can serve as a warning about potential biases in competitive funding allocation procedures and suggest the importance of secure stable funding for allowing researchers with low status to pursue their novel ideas.
\end{abstract}




\section{Introduction}

While public science systems in Europe, Japan and North America have traditionally extended significant autonomy to researches to set research priorities and (especially in Europe and Japan) imposed relatively weak evaluation criteria on that research, the New Public Management (NPM) and related movements have begun a shift in the governance of public science (Welpe et al., 2015; Whitley and Gläser, 2007). This New Public Management perspective emphasizes competitive allocation of resources and consequential evaluation of outputs (Hicks, 2012; Lewis, 2015; Whitley and Gläser, 2007). While there is significant variation in the shares of block versus competitive funding across countries, there has been a growing movement toward increasingly active governance of public research, and, in particular a debate about shifting from block to competitive allocation of funding (Geuna, 2001; Lewis, 2015; Whitley and Gläser, 2007).

This debate on block versus project-based funding of science echoes a broader debate in public administration regarding the governance perspective and the New Public Management (Page, 2005). For example, with the emergence of new administrative forms pursuing efficiency, market mechanisms have been applied to public hospital management and an organizational transformation of universities that had traditionally been considered to lack performance-based incentives (De Boer et al., 2007; Ramesh, 2008). A key focus in this debate is how best to ensure that public funds allocated to non-government entities are effectively achieving agency goals, with an increasing emphasis on performance measurement and outputs rather than inputs (Lewis, 2015). This governance perspective emphasizes the need to manage and steer the university research system toward national goals of efficiency, productivity and applicability (Lewis, 2015).

There have been increasing concerns among science policy researchers about how best to provide incentives for both productive and ground-breaking science (Bollen et al., 2013; Hicks, 2012; Ioannidis, 2011), as well as concerns for how best to document the returns to public funding (Lane et al., 2015). One dimension of this debate is whether the funding system should emphasize broad block funding for research (the German model) or whether funding should be allocated on the basis of project-level competitive grant proposals (the US model) (Capano, 2011; Geuna, 2001; Stephan, 2010). There is also a third model, with university-level competition for differential levels of block funding (the UK model) (Lewis, 2015). In addition, of course, in each country, there are variations in the mix of funding for particular projects or fields. Since around the 1980s, Europe has been moving from a block funding system to a more competitive funding system and increased industry-based funding, expecting, like in other cases of New Public Management, efficiency gains from more market-like incentives (Auranen and Nieminen, 2010; Geuna, 1999, 2001; Stephan, 2010). At the same time, there is growing concern in the US that its current funding system fails to encourage novel research: concerns that funding agencies are increasingly risk-averse, and their competitive selection procedures favor relatively safe projects at the expense of novel and risky research (Alberts, 2010; Petsko, 2012; Stephan et al., 2017). For the rest of the world, it is also uncertain whether a change to a greater emphasis 
on competitive funding would improve scientific performance (Lewis, 2015; Whitley and Gläser, 2007), and what would be a good metric by which to judge any effects (Geuna and Martin, 2003). Such a transition may also underestimate the cost of implementing a peer-reviewed, centrally monitored evaluation and allocation system (Bollen et al., 2013; Ioannidis, 2011). Geuna $(1999,2001)$ discusses some evidence that the change to the quasi-market incentive system pushes universities to do more routine contract research for industry, rather than contributing to long-term innovation, and causes inequality of funding, with substitution to large from small and medium-sized departments. Comparing country-level publication productivities, Auranen and Nieminen (2010) find no clear connection between the competitiveness of national funding systems and the efficiency of university research. Therefore, the potential effects of a change in the funding system on research performance are not straightforward.

Moreover, many studies of the relationship between funding type and research performance have focused on productivity as the main measure of performance (Auranen and Nieminen, 2010; Boyack and Börner, 2003; Himanen et al., 2009). An important exception is Azoulay et al. (2011), who focus on differences in the novelty of published research between competitive funding (National Institutes of Health grants) and long-term funding (Howard Hughes Medical Institute fellowships). Thus, in addition to differences in funding systems, there is also the question of differences in metrics.

To bring more insights into this science policy debate, in this study we analyze the relation between different funding schemes and the novelty of scientific research in Japan. As a research case, the Japanese research funding system has the advantage of providing both significant individual-level (chair) block funding, based on the German model, as well as a substantial share of competitive project funding (e.g., grants-in-aid for research) based on the US model (Kneller, 2007; Shibayama, 2011). Japanese professors have access to both block funding and competitive project funding, allowing a within country comparison of the outputs of each kind of funding. This heterogeneity of funding sources makes this a fruitful site for examining these questions.

Furthermore, we focus on novelty in research output rather than productivity. While part of the debate on the effectiveness of funding schemes revolves around productivity versus novelty (cf. Geuna, 2001), novelty has received less attention in discussion of the effect of different funding streams (Azoulay et al., 2011). Thus, while productivity or impact of research are important, these are distinct from novelty, which may have important value as an output of the science system in its own right (Azoulay et al., 2011; Lee et al., 2015; Wang et al., 2017).

We also go beyond prior work by focusing on how those in high and low status categories might be differentially affected by different funding schemes (Whitley, 2007). This focus echoes the debates on whether different funding models in the NPM affect equity in the allocation of funding. In particular, we compare high and low status scientists (comparing on rank, gender and institution type) to see if there are systematic differences in the relative novelty of their projects by funding mechanism (cf. Hermanowicz, 2009; Hesse et al., 1993; Whitley and Gläser, 2007). 
Based on a broad survey of scientists in Japan and using unobtrusive measures of the novelty of their scientific research outcomes, we first examine the relation between different funding types and novelty. We then examine whether these relations vary by the status of the scientist, with status seen as a proxy for lesser or greater vulnerability to conformity pressure. We find that, overall, competitively-funded papers have higher novelty than block-funded papers, consistent with those who argue that market-like competitive incentives will drive more effective allocation of government funding. However, among low status scientists (assistant professors, women, those outside the top seven universities), we find that novelty is relatively higher for block-funded projects, consistent with arguments that market-like mechanisms may exacerbate inequality and disadvantage vulnerable groups.

In the following sections, we develop the theories that drive our arguments on the relation between funding types and novelty and the contingent effects of vulnerability to conformity pressure. We then test our hypotheses using novel survey data about Japanese scientists and their project characteristics and research funding sources combined with a big data-based measure of novelty. We conclude with discussion of our results and the implications for policies regarding government funding of science.

\section{Funding allocation models and novelty}

Vannevar Bush argued in Science: The Endless Frontier that national science policy can be most effective if the national government funds basic scientific research and that research is executed (under contract) by universities (Bush, 1945). He further argued that research funding should be allocated based on investigator-initiated, peer-reviewed funding competitions. Empirically, Li and Agha (2015) find that the higher review scores in the National Institutes of Health (NIH) peer review, the better the research outcomes, i.e., more hit publications, more citations and more patents, suggesting that review panels are good at selecting the highest impact projects. Similarly, Park et al. (2015) compare projects funded by regular NIH budget with those additionally selected due to an unexpected increase in resources under the American Recovery and Reinvestment Act (ARRA) of 2009 and find that the former produce more publications and their publications are more cited.

While there has been interest by science agencies across the globe in adopting more competitive funding models based on the US experience (Lewis, 2015; Welpe et al., 2015; Whitley and Gläser, 2007), at the same time, there has been increasing concern that such funding mechanisms, with their emphases on feasibility and preliminary findings, may be biased toward incremental projects with high certainty over truly novel but riskier research (Alberts, 2010; Petsko, 2012; Stephan et al., 2017). Chubin and Hackett (1990) contend that quality control by peer-review drives science to conservatism, ignoring the possibility of serendipitous results or suppressing unorthodox ideas. Simonton (2003) notes that reviewers have low agreement on the quality of grant proposals, and their criteria have little predictive validity. Similarly, Kaplan et al. (2008) show that in highly competitive grant systems such as NIH in the US, the differences 
between fundable and not fundable scores are well below the threshold of reviewers' abilities to discern difference in project quality, suggesting substantial noise in the evaluation. Bornmann et al. (2010) compare funding decisions across four funding programs in Europe, including both life sciences and social sciences, and find that those who were chosen for funding tend to have higher scores, both ex ante and ex post, on various bibliometric indicators of productivity and impact (publications, $h$ index, citations). However, when comparing those who were funded with those who were nearly funded, they find that those productive scientists who were rejected by the peer review system tended to have higher productivity and impact, both ex ante and ex post. They suggest that this highlights the difficulties of allocating funding across a sample of qualified applicants, and show that such a process generates high rates of both Type I and Type II errors. Furthermore, they conjecture that selection committees may be incorporating additional unmeasured criteria, including either (or both) the novelty of the proposed project, and the status characteristics of the applicants. Moreover, as doing science becomes more transdisciplinary, heterogeneous in participating institutions, and more responsive to broader societal agendas (what Gibbons et al. call Mode 2), the peer-review process, situated in particular disciplinary criteria, would be less effective and hence require a wider range of expertise, likely making it more difficult to reach consensus on quality (Gibbons et al., 1994). Whitley and Gläser (2007) argue that high stakes evaluations systems can become captured by disciplinary elites, discouraging unorthodox approaches or research questions.

There is some evidence that peer-review in competitive project selection procedures is biased against novel proposal. Boudreau et al. (2016) find that proposal novelty is associated with lower ratings for the proposal, either because novel ideas are uncertain and distant from existing approaches, leaving evaluators steeped in more established knowledge unable to understand the novel approach, or because highly novel proposals actually have very low true quality. Using data from the UK Engineering and Physical Sciences Research Council, BanalEstanol et al. (2015) find that teams that are inclined to conduct novel research, such as new teams, teams combining researchers with diverse prior experiences, and teams including members with high mobility, are less likely to be funded.

Furthermore, the grant of competitive funding heavily relies on the past performance of the applicants while block funding is given regardless of past performance (Geuna, 2001; Stephan, 2010). Superior performance by prior grantees increases the chance of the next proposal being selected, helping these usual suspects establish a reputation for sufficient quality or productivity in their future output (Arora et al., 2000). However, as Geuna and Martin (2003) argue, funding on the basis of past performance likely pushes a research stream toward safe, conventional and homogeneous research. In addition, funding decisions and peer-review of proposals are increasingly informed by bibliometric indicators (such as citations). Wang et al. (2017) show that novel research underperforms on standard indicators, which suggests that the incorporation of such indicators of past performance into a competitive project-based allocation system is another mechanism that would further disadvantages novel research. 
In addition to the abovementioned possible inclination in the competitive funding model to select less novel project to fund (i.e., selection effect), the design of the competitive funding model may further affect the behavior of funded researchers, motivating them to shy away from risky novel research or constraining their creativity (i.e., treatment effect). Scholars have emphasized the importance of research autonomy and stable long-term funding as enabling conditions for creativity in science (Aghion et al., 2008; Heinze et al., 2009; Hollingsworth, 2004). However, in the competitive project funding model, funding recipients are committed to their proposed project and under pressures to deliver what they promised in their proposal in order to maintain a good track record, which is important for securing future funds. Such commitment and pressure may constrain their research freedom and dampen their creativity even after receiving funding (Azoulay et al., 2011).

These theoretical and empirical studies of scientific funding suggest that a competitive project funding system may suppress novelty in scientific research, although it may increase productivity and citations through more conventional research, both of which are also important performance indicators that help bring future project grants. While both novel and incremental research is important for the progress of science, there is growing concern that the current US funding system fails to support enough novel research, and this systematic bias against novelty is troublesome. For example, in the Gathering Storm report, the National Academy of Sciences highlighted these concerns and recommended more long-term funding for scientists, especially early career scientists, allowing program officers to direct funds outside of traditional peer review and more National Science Foundation (NSF) graduate fellowships (which allow graduate students more flexible funding, similar to the HHMI fellowships model). Each of these recommendations addresses concerns that the traditional competitive project-based peer review model may limit novel research, especially for junior researchers.

Thus, we see both concerns about the adverse effects of a competitive funding system and a push in many countries to increase the competitive allocation of research funding (often through a peer-review system), driven by a public management focus on increasing performance and accountability in publicly funded research. One such case of science agency reforms is Japan, which since 2004 has begun a push toward emphasizing competitive project-based funding and decreasing the share of block funding for faculty research (Kneller, 2007; Kneller, 2010). We will examine data from Japan to test these arguments, to see if the concerns raised in the case of the US and Europe (that competitive funding stifles creativity) hold in this system. In particular, we will take a snapshot of Japan and analyze a cross-section consisting of both projects funded by competitive project grants (following the US system) and those funded by internal block grants (following the German chair system). We will test whether research funded by competitive project grants generates more conventional outcome than research by noncompetitive, but more flexible block funding, as recent critiques of the US system suggest. Or, will we see evidence that the Vannevar Bush vision of a market-based New Public Management for science will address the science agencies' concerns for generating truly novel science, in support of the policy reforms in Japan and elsewhere. Therefore, our empirical test for 
Hypothesis 1 will examine whether, on average, papers resulting from competitive project-based funding are, in fact, less novel than those from block-funded projects.

H1: Projects supported by competitive funding generate less novel publications than projects supported only by block funding.

\section{Status contingency effect}

As discussed in the preceding section, the competitive funding model may favor conventional, incremental, and relative safe projects. Moreover, the vulnerability to such conformity pressures may depend on the status of the applicant. Sociologists of science have long acknowledged that the status of the author affects scientific communication; reputation of the author provides a certificate of credibility and thereby facilitates the acceptance of the discovery by peer scientists (Latour and Woolgar, 1979; Merton, 1973). The same story can be told in the process of reviewing grant proposals. Scientists with a strong academic standing have an advantage in persuading reviewers of the worthiness of their proposal (Ioannidis, 2011). Whitley and Gläser (2007) argue that conformity pressures in the face of increasingly strong governance models should be especially strong among junior scientists or others outside of the academic elite. A focus on feasibility, preliminary data and past performance also creates barriers for junior researchers who have not yet accumulated enough preliminary data (Stephan, 2010). Chubin and Hackett (1990) contend that reviewers tend to tolerate unorthodox ideas proposed by applicants with more prestigious academic background or more impressive performance records.

Researchers with low academic status may not only face a stronger selection bias against novelty in competitive project selection procedures but also suffer more from the constraint of competitive project funding on research autonomy and creativity. Goldfarb (2008) argues that researchers with higher ability can enjoy multiple funding opportunities, and hence can divert their effort, relatively more free from the constraints from the funding agency's goals, while researchers with lower ability have lower bargaining power, and hence greater need to accommodate the agency's interests and are therefore more bounded by the agency's restrictions. To the extent that status is seen as a proxy for ability (rightly or wrongly), these effects should be stronger for lower status scientists. Therefore, different statuses are associated with different levels of pressure toward conformity in proposing and executing research.

Therefore, the conformity pressure associated with competitive project funding on those of lower academic status should be greater than that on those of higher status. While those in lower, or more vulnerable, statuses may generally have pressure to conform, this may be especially true when faced with the gauntlet of peer review, where they need to convince skeptical reviewers of their worthiness for scarce funding. In a study examining the effects of lowering the constraints on researchers' access to peers and other resources, Hesse et al. (1993) find that peripheral scientists (women, younger and those at more geographically remote 
locations) differentially benefit from access to Internet-type communication networks. They term this the (positive) peripherality effect. Here, we are arguing that the same status distinctions are likely to produce a negative peripherality effect in the face of a peer-review filter to accessing grant funding, as well as in the loss of academic freedom imposed by competitive project funding. Thus, we would expect junior researchers, women, and those outside the top universities to be especially vulnerable to conformity pressures from peer review.

For example, this inequality on conformity pressure is likely to be greater among those in early career stages. Arora and Gambardella (2005) find that NSF support is more critical for principal investigators (PI) at an earlier career stage than those at a later career stage, and least critical for PIs in the middle stages. This pressure on increasing performance (usually measured by productivity) and the high vulnerability and dependence on a given resource source should push junior researchers to do more conventional research, which is safer for getting funding and generating multiple incremental papers (Hackett, 1990). Similarly, as noted above, peer reviewers may be more skeptical of submissions from those without a track record, and hence will require proposals that are closer to existing studies in order to ensure good outcomes from the research.

Similarly, female scientists are generally disadvantaged in scientific evaluation systems (Fox, 1983). In particular, in Japan, female scientists have difficulty getting full time positions and getting senior positions (Normile, 2006). Hence, we would expect female scientists to face greater pressure to produce more conventional research.

Finally, university systems are characterized by significant institutional status inequality. This may be especially true in Japan, where the prestigious core universities (Tokyo, Kyoto, Osaka, Tohoku, Nagoya, Kyushu, and Hokkaido) play an outsized role in the national research system (Kneller, 2010; Shibayama, 2011). Therefore, researchers in top universities will enjoy more autonomy for experimenting with new questions and new approaches than those in peripheral universities, because reviewers are more likely to tolerate their new approach due to their superior credentials.

In each of these cases, we expect the high-status vs. low-status gap in novelty to be much smaller in block-funded projects because researchers have more freedom in block funding, because future block funding support is not linked to prior performance, leaving researchers more free from the risks of research failure from high risk projects. Because low-status researchers using block funding are free to choose projects on their own, without having to convince a panel of peer-reviewers, block-funded projects should be less vulnerable to the conformity bias (in terms of methodology or topic) that competitive funding is argued to cause. Therefore, the effects of different statuses, associated with different levels of research constraints, will be observed more clearly and strongly when the research is supported by competitive funding than by block funding (Krimsky, 2012). Thus, we expect a significant interaction effects between funding type and academic status on novelty of research outcome, with low status researchers having lower rates of novelty (higher rates of conformity) for competitively-funded projects. This negative peripherality effect is the focus of our paper. 
Therefore, we have the following hypotheses comparing the novelty of papers published by low status researchers between block and competitive funded projects:

H2a: Junior faculty generate relatively less novel publications in projects supported by competitive funding than in block-funded projects.

H2b: Female researchers generate relatively less novel publications in projects supported by competitive funding than in block-funded projects.

$\mathrm{H} 2 \mathrm{c}$ : Researchers in peripheral universities generate relatively less novel publications in projects supported by competitive funding than in block-funded projects.

\section{The case of Japan}

There are several features of the Japanese research system that make it a particularly useful case for testing these hypotheses. First, resources are highly concentrated. As of 2010, Japan has 86 national universities, 95 universities under the jurisdiction of local governments, and 597 private universities. Although small in numbers, the national universities account for the majority of scientific research: 71\% of the Ph.D. graduates in 2009 and $67 \%$ of the Ministry of Education, Culture, Sports, Science and Technology (MEXT) Grants-in-Aid funding in 2010 (Shibayama, 2011). Within the 86 national universities, University of Tokyo (the top university), the top 7, and the top 20 account for $15 \% ; 50 \%$, and $70 \%$ of the Grants-in-Aid funding received by national universities. Second, while (until recently) junior researchers in entry positions did not have the unemployment risk of a US-style tenure track system, they had to compete to be promoted and win a position as an independent researcher (Geuna and Shibayama, 2015). Shibayama (2011) shows the inequality over career stages in Japan where the inequality among senior researchers is higher than that among junior researchers because success at the junior stage determines future research inputs leading to larger inequality among peers. Recent reforms beginning around 2000 have loosened this system of permanent employment and shifted more toward a US-style tenure track system. Third, women are extremely underrepresented in the Japanese university system (Cyranoski, 2001; Normile, 2006). In 2004, women made up $11 \%$ of the scientific workforce, the lowest among the OECD member countries, and are mostly concentrated in junior positions (Normile, 2006).

The modern Japanese national university system is modelled on the German chair system, where a chair typically consists of a full professor and a couple of assistant or associate professors. Within each chair, the full professor has very high status relative to the more junior researchers (Kneller, 2010). Each chair unit receives block funding for research (accounting for about $45 \%$ of total research funding at national universities) as part of the MEXT allocation to the university. While the bulk of the MEXT block subsidies pays for the operating costs of the university, it also includes a standard research allowance covering direct costs of research, net of 
professor salaries (Shibayama, 2011). According to Kneller (2003), at the chair level, the MEXT standard research allowance per year is on the order of $\$ 25,000 \pm \$ 10,000$. Other than the MEXT block subsidies, the competitive and peer-review based Grants-in-Aid program accounts for about $25 \%$, donations about $15 \%$, and industry contract research, foreign sources, etc. cover the remainder (Kneller, 2003). The Japanese system therefore provides a good setting for comparing these two funding allocation models. In recent years, the Japanese university system is undergoing a series of reforms, and one of the effects of the reforms is a decline in the value of the block grants and an increased emphasis on competitive project grants for funding university research (Geuna and Shibayama, 2015; Kneller, 2010; Shibayama, 2011). Hence, an analysis of the two types of funding is also timely for policy debates in Japan and elsewhere.

In sum, the Japanese system includes significant block funding as well as significant competitive project funding. There is substantial status inequality by rank, gender and institution. In addition, there is a very high level of research activity. During the period of our study, Japanese researchers were ranked near the top in terms of total number of Web of Science publications, behind only the U.S. and (in some years) the UK (Adams et al., 2010). Hence, we will use data on Japanese publications to test our hypotheses about the main effects and status contingency effects of competitive versus block funding.

\section{Data and methods}

To test these hypotheses, we use a unique dataset combining survey and bibliometric data on a large sample of scientific projects in Japan. The survey provides information from a large sample of projects spanning fields and institution types. The population of interest is researchactive faculty in the fields of sciences covered by Web of Science (WoS). The survey began with a sample of 9558 publications with at least one author affiliated with a Japanese organization, covering publication years 2001-2006, stratified by 22 WoS journal fields and by forward citations, with an oversampling of the papers in the top $1 \%$ of citations in each field in each year (citation counts retrieved December 31, 2006). About 3000 of the sampled papers were in the top-cited papers and about 6000 were from papers from the rest of the distribution.

The list of publications was searched for an appropriate Japanese contact author, beginning with the reprint author, followed by the first or last author (depending on the name ordering conventions in that field), and then going through the list of authors to find a Japanese author for whom current addresses (email or, if none available, post mail) could be found. In cases where no valid contact was available (for example, the author was deceased), we excluded those cases from the sample. Furthermore, to reduce respondent burden, for those scientists that appeared as a responding author more than once in our sample, we randomly sampled one paper, giving priority to the top-cited papers. This process led to a total of 7652 papers. We received 2081 responses leading to a $27 \%$ response rate. Response bias tests show few differences between respondents and non-respondents (e.g., on single- vs. team-authored papers, citations, publication year etc.). We further create a set of weights that account for any differential 
response and adjust to the underlying population distribution. For the detailed response bias tests, see Igami et al. (2015).

For this analysis, we limit responses to (assistant, associate and full) professors in universities and hospitals, and include all fields of science, engineering and social science $(\mathrm{N}=$ 1399). We use 20 fields merging "Economics \& Business" into "Social science, general" and reclassifying "Multidisciplinary" journal field papers into one of the 20 according to the main field of the references in the paper (See Appendix A). All statistics in this paper are calculated taking into account the sampling design and the underlying population distribution using appropriate weights (Lee et al., 1989).

The survey asked the (representing) respondent to describe the research project that produced the sampled paper (which was named on the cover of the survey), including funding information for the project. This strategy allows us to link bibliometric data about the publication to the survey data about the underlying project, in particular funding information directly linked to the project, categorized by type of funding source (block or competitive). The next section provides detailed descriptions of variable construction using these data.

\subsection{Dependent variable: Novelty}

Many prior studies measure research performance with the number of publications or citations (Geuna and Martin, 2003; Goldfarb, 2008; Himanen et al., 2009). However, the focus of this paper is on how novel the paper is, rather than how productive the researcher or research lab is or how much impact the paper has. Since an important aspect of the debate on funding systems is whether competitive funding pushes researchers toward less novel (more conventional) research, our goal is to develop a measure of the novelty of a scientific paper, to test these hypotheses.

To measure novelty of each paper as an output of a research project, we follow the combinatorial novelty literature, which views research as a problem solving process involving various combinatorial aspects so that novelty comes from making unusual combinations of preexisting components (Mednick, 1962; Nelson and Winter, 1982; Simonton, 2003). For example, Uzzi et al. (2013) examine the atypicality of referenced journal pairs in a publication. A paper has a series of referenced journal pairs with varying degrees of atypicality. Uzzi et al. (2013) record the $90^{\text {th }}$ percentile of these atypicality scores as novelty and the median as conventionality. They show that a paper with both high novelty and conventionality scores is more likely to be a highly cited paper. Using the novelty measure adapted from Uzzi et al. (2013), Lee et al. (2015) find that team size has an inverted U shaped relationship with novelty of the team output, and that this size-novelty relation is mediated by team cognitive and task variety. Wang et al. (2017) focus on more extreme cases of novelty by singling out newly appearing combinations of referenced journals as their measure of novelty. They find that novel papers are more likely to be highly cited, but also that novel papers have a higher variance in their citation performance, displaying a high risk/high gain profile. They also find that novel papers face delayed recognition and are more highly cited in other fields but not in their home 
field. In the field of biochemistry research, Foster et al. (2015) look at pairs of chemicals and find that research introducing new connections between chemicals is more likely to become highly cited but that such papers also display a higher variance in their citations. Boudreau et al. (2016) operationalize novelty of proposals as the share of Medical Subject Headings (MeSH) pairs that are new and find that evaluators are systematically biased against novel proposals. Hence, prior work suggests that coding for rare combinations of prior knowledge in the publication produces a useful measure of the a priori novelty of a scientific publication.

Following this strategy, this study adopts the same novelty measure as in Lee et al. (2015). Specifically, to create our measure of novelty of a paper (i.e., project outcome), we use the following two-step process to construct our novelty measure: 1) calculating the commonness of co-cited journal pairs for the whole WoS database and 2) calculating the novelty of our sampled papers based on their references.

The first step implements the following procedure: 1) retrieve all papers indexed in WoS, 2) retrieve all references for each paper, 3) list all pairwise combinations of references for each paper, 4) record the two paired journals for each reference pair, 5) record the publication year $t$ for each paper, and 6) pool together all journal pairs of papers published in the same year to construct a universe of journal pairs for each year. We refer to this universe of journal pairs in year $t$ as $U_{t}$. Then we define the commonness of each journal pair (journal $i$ and $j$ ) in year $t$ as:

$$
\text { Commonness }_{i j t}=\frac{\text { observed number of pairs }_{i j t}}{\text { expected number of pairs } s_{i j t}}=\frac{N_{i j t}}{\frac{N_{i t}}{N_{t}} \cdot \frac{N_{j t}}{N_{t}} \cdot N_{t}}=\frac{N_{i j t} \cdot N_{t}}{N_{i t} \cdot N_{j t}}
$$

where $N_{i j t}$ is the number of $i-j$ journal pairs in $U_{t}, N_{i t}$ is the number of journal pairs which include journal $i$ in $U_{t}$, and $N_{t}$ is the number of all journal pairs in $U_{t}$. Therefore, $\frac{N_{i t}}{N_{t}}$ is the probability that journal $i$ appears in $U_{t}, \frac{N_{i t}}{N_{t}} \cdot \frac{N_{j t}}{N_{t}}$ is the joint probability for the co-appearance of journal $i$ and $j$, and $\frac{N_{i t}}{N_{t}} \cdot \frac{N_{j t}}{N_{t}} \cdot N_{t}$ is the expected number of $i$-j journal pair.

The second step calculates novelty at the paper level. For our sampled papers, we repeat procedure (2-5) in the first step. Then for a paper published in year $t$, we record the commonness $_{i j t}$ for each of its cited journal pairs. This produces a series of commonness values, and subsequently we sort these numbers and record the $10^{\text {th }}$ percentile as an indication of the commonness at the paper level. In addition, taking the $10^{\text {th }}$ percentile instead of the minimum reduces the noise and improves the reliability of this measure. Uzzi et al. (2013) also tested the $1^{\text {st }}$ and the $5^{\text {th }}$ percentiles and demonstrated that results are robust to different cutoffs. Furthermore, we take the natural logarithm transformation to get a roughly normally distributed variable for commonness at the paper level. Then we add a minus sign to this commonness variable to give the final measure for paper novelty, since novelty is the opposite of commonness. 


\subsection{Explanatory variables}

\section{Competitive (vs. block) funding}

The survey asked the respondent about sources of research funds responsible for the sampled publication. Specifically, the survey asked them to indicate the approximate percent of total project funding that came from each of various sources (details in Appendix B). Our funding data have an advantage over other data that measure the link between funding and project based on the grants authors acknowledge in their paper. In the latter data, researchers are likely to list their grants, which are currently ongoing, in any paper they publish although the particular grant is not related to the paper or project, to increase their performance records for later funding. In addition, researchers may be unlikely to list block funding in such acknowledgements. Consistent with these concerns, Boyack and Börner (2003) recommend the data collection method of directly asking PIs about complete information on the results of a particular grant, including papers, patents and policy changes, where the starting point is a grant, and the purpose is to evaluate the outcomes of this particular grant. Our survey follows the same logic but takes a mirror approach: our starting point is a scientific publication, and we ask the main author of the paper to list direct funding sources related to the project leading to the paper, including block funding. A second advantage of this survey-based method is that it partitions the funding across different sources (reporting the percentage of the total budget of this project from that source). Thus, rather than a binary measure based on funding acknowledgments (in publications or in grant outcome reports), we can get fractional attribution across various sources. This allows for more nuanced attribution, and also allows for robustness checks across various allocation rules (see below).

Our focus is on the difference between the internal block funds and competitive project funds. Therefore, in order to have a better contrast between them, we classify projects into two types: competitively-funded vs. block-funded. Specifically, we create a dummy variable, competitively funded, which takes 1 if a project has at least $25 \%$ of funds from competitive funding and 0 otherwise. We additionally employ a continuous variable, ratio of competitive funding, as the share of funds from all sources other than internal funds. We also test alternative definitions of "block" versus "competitive" funding to see how robust our results are to different operationalizations.

\section{Academic status}

To test the hypotheses that the detrimental effect of competitive project funding on novelty is more severe for lower status researchers, we test the interaction effect between competitive project funding and academic status on novelty. We use the status of the responding author as our proxy for the status effects for the publication. While this may generate some measurement error due to misattribution of the conformity pressures (for example, if the responding author was a junior first author who is collaborating with a senior second author), we argue that these are tolerable for two main reasons. The first is that we suspect that the responding author (generally the first, corresponding or last author) is most responsible for the 
project and hence the status effects are likely reflected in his or her status (especially for competitive funding, where the low-status person can be the PI). While some may argue that block funding is largely under the control of the senior member of a chair unit, it is the junior people who may be responsible for proposing specific paper ideas, and whose careers depend on the productivity and novelty of their projects, and hence the observed publications for which the junior person is the responding author are likely to reflect his or her inputs. ${ }^{1}$ The second reason that this measure is likely to be sufficient is that misattribution (coding a paper as by a low-status author when it was under the direction of a high-status author) would likely attenuate any observed effects, giving us a conservative test of our interaction effect hypotheses. Therefore, we use the status of the responding author to create three different operationalizations of status, using academic rank, gender, and university prestige. Specifically, we construct three dummy variables based on survey information about the responding author.

First, for academic rank we construct a dummy variable, junior (vs. senior) researchers, which is 1 if the responding author is an assistant professor and 0 if associate or full professor. Since junior researchers have to compete to be promoted, assistant professors should have greater conformity pressures, due to their lower and more vulnerable status.

The second dummy variable is female (vs. male) researcher, which is 1 if the responding author is female and 0 if male. The Japanese university system has a very high level of gender inequality, and female researchers are extremely underrepresented. Furthermore, their rate of promotion to higher status positions is also disproportionately low. Hence, again, we would argue they are more vulnerable to conformity pressures.

Third, for university prestige we construct a dummy variable, peripheral (vs. core) universities, equal to 1 if the survey respondent is not affiliated with one of the seven major national universities in Japan, i.e., the former Imperial universities: Hokkaido, Kyoto, Kyushu, Nagoya, Osaka, Tohoku, and Tokyo, and 0 if in these top 7 (core) universities. These core universities are considered exceptionally prestigious for research and account for about half of all the research grants from the Japanese government. Hence, researchers from outside these universities (which we term peripheral universities) may face greater conformity pressures in their attempts at garnering competitive grant funding. Obviously, there are many good faculty and universities (especially specialist universities that might be quite good in one or another field) in this set of peripheral universities. However, we are arguing that they are likely, on average, to face greater conformity pressure than those in the core (top 7) universities. To the extent that this is not the case, our results are likely to be attenuated.

\subsection{Control variables}

Since team size might be related to the status of the team leader, sources of research funds, and novelty of the research output, we control for the log number of authors on the publication. International collaboration might also be related to our dependent and explanatory

\footnotetext{
${ }^{1}$ In some departments, even this funding is allocated directly to each faculty member, across the ranks (the so-called small chair system), further reducing this potential for bias.
} 
variables. More importantly, collaborating with leading countries in science might differ from collaborating with scientific followers. For example, previous studies observed a performance premium associated with collaborating with US researchers (Crespi and Geuna, 2008).

Therefore, we categorize different types of international collaborations, specifically: (1) collaborating with the US; (2) collaborating with Western Europe; (3) collaborating with the rest of the world; and (4) domestic publications without international collaborations. Furthermore, we control for the log number of WoS references, as our novelty measure is based on a paper's references registered in the WoS and therefore might be related to the number of references. In addition, we also control for publication year and field differences.

\section{Results}

\subsection{Descriptive statistics}

The survey asked about the source of research funds for the project and collected information on the percentage from various sources. Summary statistics are reported in Table 1. The most important source is internal funds, which on average contribute $41 \%$ to the total research funds for the project. The second most important source is the competitive MEXT Grants-in-Aid (GIA) program, accounting for 33\% of the total research funds. Note that Grantsin-Aid includes a variety of funding mechanisms, some of which are much more competitive than others. Unfortunately, we do not have data on which of the funding programs (within the GIA scheme) funded the observed paper. It may be the case that the GIA funding that low status researchers received comes from the less competitive programs and the funding that the high status people receive comes from the more competitive programs. If this is the case, then we would expect the conformity pressures to be lessened for the low status people who are proposing to the moderately (rather than highly) competitive funding programs. However, such differentiation in the "competitiveness" of the competitive funding would dampen any status contingency effects (comparing non-competitive internal funding to competitive external funding), decreasing the chances of observing significant effects for our H2s. Hence, if we still observe significant effects in the face of such possible measurement error, this suggests a strong status contingency effect. None of the other sources exceeds $5 \%$, indicating their lower contribution in the funding system. This funding composition is in line with prior literature (described above) that, while internal funds serve as the largest source of research budget, competitive funds, in particular the MEXT Grants-in-Aid program, also play an important role in the Japanese science system. For our focal funding variable, we classify a project as competitively funded when it has at least $25 \%$ of funds from sources other than internal funds, and about $75 \%$ projects are classified as competitively funded (Table 2 ). The other funding variable is the ratio of competitive funds, which is the ratio of total funds that are from noninternal sources, and it ranges from 0 to 1 , with the mean of 0.59 and standard deviation of 0.37 . 
Descriptive statistics of all other variables are reported in Table 2. In our sample, about $21 \%$ of publications are led by junior researchers, and $72 \%$ by researchers outside the seven prestigious national universities. Furthermore, only $5 \%$ of publications are led by female researchers, in line with the high gender inequality in the Japanese academic system. In terms of international collaboration, about $10 \%$ of publications are coauthored with American scientists, $6 \%$ with Western European scientists, and 10\% with other countries. Note that these categories are not mutually exclusive since a publication can be coauthored with both American and Western European scientists, for example. In total $77 \%$ of publications involve only Japanese researchers.

Novelty is positively correlated with competitively funded (0.08), ratio of competitive funds (0.11), team size (0.30), and the number of references (0.27). However, our three measures of low status are not correlated with novelty. Competitively funded is positively correlated with the number of references $(0.17)$ but negatively correlated with low status.

\subsection{Regression results}

Table 3 reports the results of OLS models predicting novelty of the publication. Before reporting the effect of competitive funding on novelty, Table 3 column 1 first reports the results of a baseline model only with controls and academic status variables. As expected, the numbers of authors and references have a positive relation with novelty. The effects of international collaboration are not significant. More importantly, there is no significant difference between junior and senior researchers, or between male and female researchers. This is a key finding, suggesting no difference in the overall novelty of papers across gender or rank. The effect of peripheral universities, on the other hand, is significantly negative, indicating that research led by researchers from prestigious universities is more novel.

Insert Table 3 about here

To test Hypothesis 1, in Table 3 column 2 we add the dummy variable, competitively funded. Our hypothesis is that projects supported by competitive funding would suffer from conformity pressure, and so would be less novel on average. We find, instead, a significant and positive effect, suggesting that publications resulting from competitive funds are more novel than publications produced from block funds. This finding does not support our first hypothesis. Our result rather shows that in the Japanese context, the competitive selection procedure does support novel ideas, consistent with arguments from Vannevar Bush and others advocating for more competitive funding, as suggested by the NPM strong governance agenda (Whitley and Gläser, 2007). Therefore, there is some evidence that a competitive selection procedure in science, as a quality control mechanism, is working the way it is intended to (Li and Agha, 2015), although 
more evidence is required to assess the efficacy of a competitive selection procedure in research funding.

In the next step we test whether the effect of competitive funding on novelty differs between high and low status researchers (columns 3-5). Our hypotheses are that the conformity pressures will be stronger for low status researchers (junior, female or those at peripheral universities). Thus, we expect a negative interaction effect in each case. We find that the main effect of competitive funding remains positive and significant, whereas the interaction effects between competitive funding and low status are consistently negative (significantly so for junior and female researchers), consistent with the argument that low status researchers face greater conformity pressures under competitive funding systems (our second set of hypotheses). This suggests that the positive effect of competitive funding on novelty only holds for high status researchers in more secured positions, but not for low status researchers. This is consistent with our arguments that low status researchers will be more vulnerable to conformity pressures in peer review.

The sign of the effect for peripheral institution in column 5 is also negative, but not significant at the conventional level (with p-value, 0.21). Although we do not find significant support for $\mathrm{H} 2 \mathrm{c}$, the direction of the results across all three measures of status are consistent, giving us greater confidence in our theory of status and conformity pressures. For further interpretation, we need to consider the implications of Type I and Type II errors (Aguinis et al., 2010). In our case, concluding that there is no interaction effect (between being competitively funded and being in peripheral universities) on novelty when in fact there is one (i.e., Type II error) could encourage the research funding system in Japan to shift from block funding to competitive funding, handicapping scientists in peripheral universities. In contrast, concluding that there is an interaction effect when in fact there is not (i.e., Type I error) would maintain the status quo in the face of little evidence that low-status scientists benefit from competitive funding. In other words, while the evidence that this category of low status scientist has a negative result in a competitive funding system is weak, there is no evidence that this category (nor either of the other two) has a positive result. Hence, in our case, a Type II error would be more serious than a Type I error, which means we may have to take a more liberal view toward a Type I error. This asymmetry of impacts combined with the consistency across different measures of our status variable, suggests that the inference that low status researchers have less novel outcomes in a competitive funding system is more reasonable.

Based on Table 3 columns 2-5, Fig. 1 estimates the average novelty of publications from block-funded projects and competitively funded projects, by different status groups, and provides a visual representation of the interaction effects. The Figure shows that scientists in low status positions exert their creativity better when supported by flexible block funding than by competitive funding. In addition, Table 3 columns 6-9 replicate columns 2-5, using the ratio of competitive funding, and shows very similar results. 


\subsection{Selection effect vs. treatment effect}

Given our research design, we cannot clearly distinguish between a selection effect and a treatment effect as the drivers of the relations between funding and outcomes, for high status and low status researchers. Given our theories of market-like competition combined with differential conformity pressures, we suspect both effects exist. However, we also present some additional tests to try to untangle these two effects.

The observed higher novelty associated with competitively funded project (our main effect) could be because competitive funding systems select more novel ideas to fund (selection effect) or because receiving the competitive funds changes the course of the research and makes it more novel (treatment effect). In addition, we observe that competitive funding has a more negative effect on novelty for researchers with lower academic status (our interaction effects). The question remains whether this is because the competitive project selection procedures, in particular peer review, are less receptive to novel proposals from researchers with lower status, or because receiving competitive funds changes the behavior of researcher with lower status, shifting them more away from pursuing novel opportunities due to the lack of research freedom or management skills.

To untangle the selection and treatment effects, we split our sample into two sections: projects that changed course in the process and those that did not. The intuition is that, if the project proceeded exactly as it was initially planned, then receiving competitive funding (or not) did not change the course of the project and therefore did not have a treatment effect, and the observed differences are only due to the selection effect. On the other hand, if the project proceeded significantly differently from how it was initially planned, then the novelty of the final output may reflect the treatment of getting the project funding, in addition to selection.

Specifically, we use additional information from the survey, which asked "Did the research project that yielded the focal paper proceed as initially planned?", with answers on a five point scale from '1: Largely the same as originally planned' to '5: Quite different than originally planned'. The distribution of the responses from 1 to 5 are: $29 \%, 34 \%, 20 \%, 13 \%$, and $4 \%$, respectively. We construct a dummy variable process changed, which takes 1 if the response is 3, 4 or 5 and takes 0 if the response is 1 or 2 . The first observation is that process change does not have any significant effect on novelty (Table 4 column 1), reassuring that the process change is not correlated with novelty.

Insert Table 4 about here

Subsequently, we partition the sample into two parts: (1) process unchanged projects (process changed $=0$ ) and (2) process changed projects (process changed $=1$ ). Subset $(1)$ can be used for estimating the selection effect, while the difference in the estimates between subset (1) and (2) can be used for making inference about the treatment effect. It is important to note that this approach is imperfect, for example, the results in subset (1) is probably dominated by 
but not purely consisting of the selection effect. Nevertheless, even with significant measurement error, comparing these two sets of results can be informative.

In terms of the main effect of competitively funding (vs. block funding) on novelty, on the one hand, Table 4 column 2 confirms a positive selection effect, on the other hand, the difference between the coefficient of competitively funded in columns 2 and 6 is insignificant, indicating no significant treatment effect. It suggests that in general, competitive funding leads to more novel publications because it selects more novel ideas to support but does not stimulate further creativity in its recipients.

With regards to status contingency effects, Table 4 columns 3-5 and 7-9 seem to suggest the existence of both a selection and treatment effect. In particular, in columns 7 and 8 , we see a negative interaction effect for the low status measures (junior, female), and in each case the magnitude of the effect is larger than for the process unchanged (selection effect) regressions. The difference is significant $(\alpha=0.10)$ for junior, but not for female. Thus, both the selection and treatment bias against novelty is significantly stronger for junior than senior researchers. In other words, the results suggest that the competitive project selection procedure is less receptive to novel ideas from junior researchers, and that junior researchers become less novel after receiving competitive funds. One possibility is that competitive funding constrains their flexibility and creativity, perhaps because of stronger concerns about delivering what they promised in the proposal. Or, perhaps, it is because junior scientists lack management skills and so are overly burdened by the administrative aspects of the externally funded project and cannot devote enough time to improving the creativity of the outputs. We see a similar pattern for gender, although the effect in the selection condition is not statistically significant at conventional levels and the difference in the two models is not significant. For university rank, we observe a significant negative selection bias against researchers from peripheral universities, indicated by a significantly negative interaction effect in Table 4 column 5, while the treatment effect of competitive funding on their novelty is positive. In other words, the competitive selection procedure is indeed biased against peripheral universities when it comes to novelty, but receiving competitive funds does not have an additional negative effect on their novelty.

Thus, to the extent that we can unpack the selection and treatment effects, we see strong evidence of a positive selection effect for high status researchers and a negative selection effect for low status researchers, reinforcing our arguments above. We also see some evidence of an additional negative treatment effect for junior and, possibly, female researchers, suggesting that the competitive funding mechanisms may also push these researchers toward more conventional research after receiving the grant. While we are not sure of the mechanisms, it is possible that either a strong desire to deliver what they promised in the proposal or limited skills in administering such grants, in particular, less skill in flexibly applying what may seem to be formally rigidly controlled funds, might explain these differences. Of course, this test involves some perhaps heroic assumptions (about our ability to distinguish selection from treatment based on grouping according to our process change measure) and hence further work is needed to distinguish more clearly between the effects and possible mechanisms. 


\subsection{Robustness tests}

We use variations on our explanatory and dependent variables to test the robustness of our findings. For the funding variables, we also tried two other variations of the competitive funding dummy variable: (a) competitive funding defined as all funds other than internal or private donation and (b) competitive funding defined as all funds other than internal, private donation, or other non-competitive funding (results available from contact author). Our results are robust to using these variations, except that the interaction effect between competitive funding and being female become insignificant, although still negative and sizeable.

For novelty, we also tried a different novelty measure that defines novel papers as those which make new combinations of referenced journals, following Wang et al. (2017). We run probit regressions using this dummy variable (i.e., those with vs. without new combinations of journal references) and obtained robust results.

We also ran our models in Table 3 excluding social sciences and obtain consistent results. In addition, we ran models controlling for project budget (as an additional measure of project size), in addition to number of authors. Again, we find that the results are robust.

\subsection{Alternative explanations}

The main finding of this paper is the negative interaction effects between competitive funding and low status on novelty. Our explanation is two-fold. First, the peer review system for funding decisions is less receptive to novel ideas from researchers with low academic status than that from researchers with high status. In other words, researchers with low status face a greater obstacle in securing competitive project funds for their novel ideas. Second, receiving competitive funds might constrain the flexibility and creativity of the research, especially for researchers with lower status. However, there may be alternative explanations for our results. We address several of these below.

One alternative explanation is that those who receive competitive funding are just better than others, so that research supported by competitive funding shows high novelty. Although this may be consistent with the main effect (i.e., the effect of competitive (vs. block) funding on novelty), it does not explain how, among junior or women scientists, research outcomes supported by competitive funding show lower novelty than those by block funding.

One may also argue that people choose to submit the more novel projects for competitive funding. Again, while this is consistent with the main effect, it does not explain why the junior and women researchers are self-selecting the less novel projects. There could be self-screening, such that PIs pick projects they think are likely to get competitive funding, that is, senior or male scientists pick novel projects, while junior or female scientists pick conventional projects. However, this is simply another way of stating our argument on the vulnerability to conformity pressure for scientists with low academic credentials.

An additional alternative explanation is that projects with block funding might in fact include higher average novelty, but also be more likely to fail (that is, not produce any papers) so 
that we disproportionately observe higher novelty in projects with competitive funding. This may explain the main effect, but still cannot explain the interaction effect in our model, because based on this differential survival argument, to explain our interaction effect, the justification would have to be the case that for junior or female scientists, the novel projects with competitive funding should fail at a higher rate than the novel projects with block funding (while the opposite is true for senior and male scientists).

Thus, alternative explanations may explain the main effect, but do not hold for both the main and the interaction effect. Therefore, these alternative explanations are unlikely to negate our arguments to explain the relationships among funding types, high vs. low status and novelty.

\section{Conclusion}

This paper analyzes the relation between funding schemes and the novelty of scientific outputs. Specifically, we compare the differences in novelty between publications (i.e., projects) funded by competitive project funds and those funded by internal block funds. We choose Japan as the setting for this study because Japan is one of the leading countries in science and has sufficient heterogeneity in terms of funding sources in its university system to make these comparisons. Using a rich dataset combining survey data on a large sample of scientific projects in Japan and bibliometric data about the publications produced from these projects, we find that competitive project funding has a much higher negative effect on novelty for researchers with low academic status than for researchers with high status, suggesting that the peer-review system for funding decisions is less receptive to novel ideas proposed by researchers with low status and therefore is less likely to fund them (or they are less likely to submit). Therefore, scientists with low status benefit more from internal block funding.

One limitation of the study is that we do not have data on all proposals submitted for funding. Therefore, we cannot distinguish between lower novelty as a result of low status researchers only submitting their more conventional ideas to funding agencies, or lower novelty because researchers are submitting all (or a random set) of proposals and the reviewers are differentially selecting the conventional proposals from low status researchers. Since both explanations depend on a shared understanding of a differential conformity bias by the researchers' academic credentials, we view these as two sides of the same coin. Still, it would be interesting in future work to get a sample of proposal submissions by high and low status PIs and see if the funding decisions reflect relatively higher or lower conformity bias by PI status. In addition, our status measures are based on group membership (male vs. female; junior vs. senior; core university vs. other). Further work could examine individual measures of high vs. low status based on past performance to see if these arguments generalize to comparisons of eminent vs. less eminent scientists. There is also the limitation of the generalizability of our results found in Japan to other countries that perhaps have less emphasis on seniority and/or gender. Future studies need to compare across different characteristics of countries' academic systems to test the generalizability of these findings. 
We also have the limitation that we are using the Web of Science as our sampling frame. To the extent that researchers in Japan publish in Japanese journals, which may be underrepresented in the WoS, we are not capturing all of the possible publications that were funded by each funding source. This limits the generalizability of our findings to those publications that appear in the Web of Science. In particular, if there are particular types of publications that are (differentially) funded by either internal block or external competitive funding, and/or if there is an interaction effect between status and publication outlet, then our sampling method will not capture this (cf. Chavarro et al., 2017). Future work that captures a broader set of scientific outputs would help address this limitation.

Another limitation is that this paper does not provide a conclusive answer in terms of which funding model is "better." Answering this question requires taking into account many other factors. On the one hand, block funding may distribute resources to less novel or less productive scientists. Targeting funding to the most productive scientists or most novel project proposals is one of the goals of the NPM of science. However, our findings suggest that in practice such systems may systematically favor high status scientists and may exacerbate existing status distinctions in science. In addition, the peer-review based competitive project funding system costs researchers a huge amount of time for writing proposals, evaluating others' proposals, and administrating the project, which crowds out time for research. Furthermore, in countries such as the United States, where the success rate for competitive funding programs keeps decreasing, researchers have to write more proposals and in turn review more proposals. Such costs need to be taken into account when evaluating different funding models. This paper has a focused, narrow research question, that is, which funding model supports more novel research, and for whom. Although it does not provide a conclusive answer for which funding model is "better," it is an important initial step for a full cost-benefit analysis on different funding models.

This study makes several contributions to the study of funding systems' effects on scientific performance. First, while previous literature mostly focuses on productivity or impact of funded individuals or labs, we study the effect of funding schemes on the type of output, in particular, its novelty, an important driver of scientific progress. Second, while most previous studies try to quantify returns from some specific funding programs or compare across countries with different funding systems, we compare two distinct funding models, internal block funding and competitive project funding systems, within the same science system. This study is particularly relevant to the ongoing debates across the globe on the merits of shifting the scientific funding system toward a more competitive funding system.

Our findings have important implications for funding policies in science. Peer review plays a very important role in funding allocation. However, prior studies point to the evaluation biases in peer review. For example, Boudreau et al. (2016) find that evaluators systematically give lower scores to research proposals that are closer to their own areas of expertise and to those that are highly novel. In this study we further demonstrate that the bias against novel research also depends on the status of the applicants and is particularly pronounced for applicants with 
low status, while at the same time not finding such a bias for high status scientists (unlike some prior work from the US). Such bias needs to be accounted for, in order to ensure the sound functioning of the peer review systems for funding decisions.

Furthermore, the findings also warn about potential costs from a transition from an internal block funding system to a competitive funding system. The latter might be able to deliver a more efficient system (in terms of papers per funding dollar) for producing science but may further marginalize researchers already with unsecured positions such as junior and female researchers, who will face greater obstacles in securing competitive funds for their novel research. Stable internal funds are vital to allow them to pursue their novel ideas. Like similar arguments in the NPM about the benefits of market-like funding allocation, and also the need to incorporate flexibility and local context, these results suggest that science agency management and agenda setting needs to balance the needs for control and targeting resources through competitive peer review with the need to encourage experimentation, flexibility and support for a variety of perspectives on science. These findings are consistent with arguments that the US NSF should fund more graduate fellowships rather than research assistant positions, on the argument that young researchers with their own flexible block funding not tied to a specific research project may be better able to pursue novel research streams at a time when they are especially vulnerable to conformity pressures (NAS, 2006). The potential damage is not only about individuals with less secure positions in the status system, but also about the long term progress of science at large. Discouraging novel ideas from junior researchers, female researchers and researchers outside a few prestigious universities wastes a considerable amount of creative resources in the scientific labor force. In addition, today's junior researchers are tomorrow's scientific leaders, and discouraging junior researchers' novelty may imperil long term scientific progress. 


\section{References}

Adams, J., King, C., Miyairi, N., Pendlebury, D., 2010. Global research report japan. Leeds, UK: Thomson Reuters.

Aghion, P., Dewatripont, M., Stein, J.C., 2008. Academic freedom, private-sector focus, and the process of innovation. The RAND Journal of Economics 39, 617-635.

Aguinis, H., Werner, S., Abbott, J.L., Angert, C., Park, J.H., Kohlhausen, D., 2010. Customer-centric science: Reporting significant research results with rigor, relevance, and practical impact in mind. Organizational Research Methods 13, 515-539.

Alberts, B., 2010. Overbuilding Research Capacity. Science 329, 1257-1257.

Arora, A., David, P.A., Gambardella, A., 2000. Reputation and competence in publicly funded science: estimating the effects on research group productivity, The Economics and Econometrics of Innovation. Springer: New York, pp. 141-176.

Arora, A., Gambardella, A., 2005. The impact of NSF support for basic research in economics. Annales d'Economie et de Statistique, 91-117.

Auranen, O., Nieminen, M., 2010. University research funding and publication performance-An international comparison. Research Policy 39, 822-834.

Azoulay, P., Graff Zivin, J.S., Manso, G., 2011. Incentives and creativity: evidence from the academic life sciences. The RAND Journal of Economics 42, 527-554.

Banal-Estanol, A., Macho-Stadler, I., Perez-Castrillo, D., 2015. Key success drivers in public research grants: Funding the seeds of radical innovation in academia. working paper.

Bollen, J., Crandall, D., Junk, D., Ding, Y., Börner, K., 2013. Collective allocation of science funding: from funding agencies to scientific agency. arXiv preprint arXiv:1304.1067.

Bornmann, L., Leydesdorff, L., Van den Besselaar, P., 2010. A meta-evaluation of scientific research proposals: Different ways of comparing rejected to awarded applications. Journal of Informetrics 4, 211-220.

Boudreau, K.J., Guinan, E.C., Lakhani, K.R., Riedl, C., 2016. Looking Across and Looking Beyond the Knowledge Frontier: Intellectual Distance, Novelty, and Resource Allocation in Science. Management science.

Boyack, K.W., Börner, K., 2003. Indicator-assisted evaluation and funding of research: Visualizing the influence of grants on the number and citation counts of research papers. Journal of the American Society for Information Science and Technology 54, 447-461.

Bush, V., 1945. Science: The endless frontier. Transactions of the Kansas Academy of Science (1903-) 48, 231-264.

Capano, G., 2011. Government continues to do its job. A comparative study of governance shifts in the higher education sector. Public Administration 89, 1622-1642.

Chavarro, D., Tang, P., Ràfols, I., 2017. Why researchers publish in non-mainstream journals: Training, knowledge bridging, and gap filling. Research Policy 46, 1666-1680.

Chubin, D.E., Hackett, E.J., 1990. Peerless science: Peer review and US science policy. Suny Press.

Crespi, G.A., Geuna, A., 2008. An empirical study of scientific production: A cross country analysis, 1981-2002. Research Policy 37, 565-579.

Cyranoski, D., 2001. 'One woman is enough...'. Nature 410, 404-406.

De Boer, H.F., Enders, J., Leisyte, L., 2007. Public sector reform in Dutch higher education: The organizational transformation of the university. Public Administration 85, 27-46.

Foster, J.G., Rzhetsky, A., Evans, J.A., 2015. Tradition and Innovation in Scientists' Research Strategies. American Sociological Review 80, 875-908.

Fox, M.F., 1983. Publication productivity among scientists: A critical review. Social studies of science $13,285-305$.

Geuna, A., 1999. The Economics of Knowledge Production. Cheltenham and Northampton: Edwart Elgar. 
Geuna, A., 2001. The changing rationale for European university research funding: are there negative unintended consequences? Journal of economic issues, 607-632.

Geuna, A., Martin, B.R., 2003. University Research Evaluation and Funding: An International Comparison. Minerva 41, 277-304.

Geuna, A., Shibayama, S., 2015. Moving Out Of Academic Research: Why Scientists Stop Doing Research? The University of Tokyo GraSPP Working Paper GraSPP-DP-E-15-002 and STIGDP-E-15-002.

Gibbons, M., Limoges, C., Nowotny, H., Schwartzman, S., Scott, P., Trow, M., 1994. The new production of knowledge: The dynamics of science and research in contemporary societies. Sage.

Goldfarb, B., 2008. The effect of government contracting on academic research: Does the source of funding affect scientific output? Research Policy 37, 41-58.

Hackett, E.J., 1990. Science as a vocation in the 1990s: The changing organizational culture of academic science. The Journal of Higher Education, 241-279.

Heinze, T., Shapira, P., Rogers, J.D., Senker, J.M., 2009. Organizational and institutional influences on creativity in scientific research. Research Policy 38, 610-623.

Hermanowicz, J.C., 2009. Lives in Science: How Institutions Affect Academic Careers. University of Chicago Press, Chicago.

Hesse, B.W., Sproull, L.S., Kiesler, S., Walsh, J.P., 1993. Returns to science: computer networks in oceanography. . Communications of the ACM 36, 90-101.

Hicks, D., 2012. Performance-based university research funding systems. Research Policy 41, 251-261.

Himanen, L., Auranen, O., Puuska, H.-M., Nieminen, M., 2009. Influence of research funding and science policy on university research performance: A comparison of five countries. Science and Public Policy 36, 419-430.

Hollingsworth, R., 2004. Institutionalizing excellence in biomedical research: The case of Rockefeller University, Creating a Tradition of Biomedical Research: The Rockefeller University Centennial History Conference, pp. 17-63.

Igami, M., Nagaoka, S., Walsh, J.P., 2015. Contribution of postdoctoral fellows to fast-moving and competitive scientific research. The Journal of Technology Transfer 40, 723-741.

Ioannidis, J.P., 2011. More time for research: fund people not projects. Nature 477, 529-531.

Kaplan, D., Lacetera, N., Kaplan, C., 2008. Sample Size and Precision in NIH Peer Review. PLoS ONE $3, \mathrm{e} 2761$.

Kneller, R., 2003. University-industry cooperation and technology transfer in Japan compared with the United States. U. Pa. J. Int'l Econ. L. 24, 329.

Kneller, R., 2007. Prospective and retrospective evaluation systems in context: insights from Japan, in: Whitley, R., Glaser, J. (Eds.), Changing Governance of the Sciences: the Advent of Research Evaluation Systems. Springer, Dordrecht, Netherlands, pp. 51-73.

Kneller, R., 2010. The changing governance of Japanese public science, Reconfiguring Knowledge Production: Changing Authority Relations in the Sciences and their Consequences for Intellectual Innovation. Oxford Scholarship Online, pp. 110-145.

Krimsky, S., 2012. Do financial conflicts of interest bias research? An inquiry into the " funding effect'hypothesis. Science, Technology \& Human Values 38, 566-587.

Lane, J., Owen-Smith, J., Rosen, R., Weinberg, B., 2015. New Linked Data on Research Investments: Scientific Workforce, Productivity, and Public Value. Research Policy.

Latour, B., Woolgar, S., 1979. Laboratory life Ca: Sage Beverly Hills.

Lee, E.S., Forthofer, R.N., Lorimor, R.J., 1989. Analyzing Complex Survey Data. Sage, Newbury Park, CA.

Lee, Y.-N., Walsh, J.P., Wang, J., 2015. Creativity in scientific teams: Unpacking novelty and impact. Research Policy 44, 684-697.

Lewis, J.M., 2015. Research Policy as "Carrots and Sticks": Governance Strategies in Australia, the United Kingdom and New Zealand, Varieties of Governance. Springer, pp. 131-150. 
Li, D., Agha, L., 2015. Big names or big ideas: Do peer-review panels select the best science proposals? Science 348, 434-438.

Mednick, S.A., 1962. The associative basis of the creative process. Psychological Review 69, 220-232.

Merton, R.K., 1973. The sociology of science: Theoretical and empirical investigations. University of Chicago press.

NAS, 2006. Rising above the gathering storm: Energizing and employing America for a brighter economic future. National Academies Press Washington, DC.

Nelson, R.R., Winter, S.G., 1982. An Evolutionary Theory of Economic Change. Belknap Press of Harvard University Press, Cambridge, MA.

Normile, D., 2006. WOMEN IN SCIENCE: Getting Women Scientists Back on the Career Track in Japan. Science 311, 1235-1236.

Page, S., 2005. What's new about the New Public Management? Administrative change in the human services. Public Administration Review 65, 713-727.

Park, H., Lee, J., Kim, B.-C., 2015. Project selection in NIH: A natural experiment from ARRA. Research Policy 44, 1145-1159.

Petsko, G.A., 2012. Goodbye, Columbus. Genome Biology 13, 155.

Ramesh, M., 2008. Autonomy and control in public hospital reforms in Singapore. The American Review of Public Administration 38, 62-79.

Shibayama, S., 2011. Distribution of academic research funds: a case of Japanese national research grant. Scientometrics 88, 43-60.

Simonton, D.K., 2003. Scientific creativity as constrained stochastic behavior: the integration of product, person, and process perspectives. Psychological Bulletin 129, 475-494.

Stephan, P.E., 2010. The economics of science-funding for research. International Centre for Economic Research Working Paper.

Stephan, P.E., Veugelers, R., Wang, J., 2017. Blinkered by bibliometrics. Nature, 411-412.

Uzzi, B., Mukherjee, S., Stringer, M., Jones, B., 2013. Atypical combinations and scientific impact. Science 342, 468-472.

Wang, J., Veugelers, R., Stephan, P.E., 2017. Bias against novelty in science: A cautionary tale for users of bibliometric indicators. Research Policy 46, 1416-1436.

Welpe, I.M., Wollersheim, J., Ringelhan, S., Osterloh, M., 2015. Incentives and performance. Governance of research organizations, Cham [etc.].

Whitley, R., Gläser, J., 2007. The changing governance of the sciences: The advent of research evaluation systems. Springer Dordrecht. 


\section{Appendix A: Field lists}

Table A1. Journal fields for WoS

1. Agricultural science

2. Biology \& Biochemistry

3. Chemistry

4. Clinical medicine

5. Computer science

6. Environment/Ecology

7. Economics \& Business

8. Engineering

9. Geosciences

10. Immunology

11. Materials science

12. Mathematics

13. Microbiology

14. Molecular biology \& Genetics

15. Multidisciplinary

16. Neuroscience \& Behavior

17. Pharmacology

18. Physics

19. Plant \& Animal science

20. Psychiatry/Psychology

21. Social sciences, general

22. Space sciences

For post-stratification for sampling weights, we merge Economics \& Business into Social sciences, and assign Multidisciplinary into one of disciplinary fields. Therefore, we use 20 fields for field controls with Chemistry as the reference group. 


\section{Appendix B: Survey instrument: Sources of research funds}

Please inform us about the source of research funds for the project. Indicate the approximate percentage of each of the following sources that apply.

(a) Internal funds - Funds of the institution that the research team members belong to (domestic or foreign)

(b) Center grants (such as $21^{\text {st }}$ Century COE, etc.) from the central Japanese government Competitive Research grants for projects (c-g)

(c) Grants-in-aid for Scientific Research

(d) Health and Labor Science Research Grants

(e) Japan Science and Technology Agency

(f) New Energy and Industry Technology Development Organization (NEDO)

(g) Other competitive project grants from a government

(h) Non-competitive research grants (such as a national project led by the government)

(i) External funds from local Japanese Government

(j) External funds from foreign government

(k) Commissioned research from Japanese firms

(l) Collaborative research with Japanese firms

(m) Donations from Japanese firms

(n) Other funding from Japanese private enterprises

(o) External funds from foreign firms

(p) Other (such as Foundations)

\# Regarding the research money that national universities and public research institutions received from the government (excluding competitive research funds), if you cannot determine whether the funds are internal to your institution or are other external funds (government), choose non-competitive research grant if the funds are tied to specific research subjects, and choose internal funds of your institution if they do not target a specific subject. \# When national research funds were allocated via a foundation, choose external funds from central Japanese Government (including independent administrative institutions). \# If the headquarters of the firm is located in Japan (abroad), please identify the fund as "External funds from Japanese (foreign) firm." 


\begin{tabular}{lrr}
\hline & Mean & Std. Dev. \\
\hline Internal funds - Funds of the institution that the research team members belong to (domestic or foreign) & 40.92 & 37.24 \\
Center grants (such as 21st Century COE, etc.) from the central Japanese government & 3.97 & 14.41 \\
Grants-in-aid for Scientific Research & 32.54 & 34.43 \\
Health and Labor Science Research Grants & 1.17 & 7.08 \\
Japan Science and Technology Agency & 3.56 & 13.77 \\
New Energy and Industry Technology Development Organization (NEDO) & 1.27 & 8.37 \\
Other competitive project grants from a government & 2.87 & 13.45 \\
Non-competitive research grants (such as a national project led by the government) & 0.97 & 8.28 \\
External funds from local Japanese Government & 0.49 & 4.40 \\
External funds from foreign government & 1.50 & 9.34 \\
Commissioned research from Japanese firms & 1.16 & 6.40 \\
Collaborative research with Japanese firms & 1.71 & 8.77 \\
Donations from Japanese firms & 4.32 & 14.39 \\
Other funding from Japanese private enterprises & 0.31 & 4.08 \\
External funds from foreign firms & 0.71 & 6.12 \\
Other (such as Foundations) & 2.54 & 11.22 \\
\hline
\end{tabular}


Table 2. Descriptive statistics and correlations

\begin{tabular}{|c|c|c|c|c|c|c|c|c|c|c|c|c|c|c|c|c|}
\hline & Variable & $\mathrm{N}$ & Mean & Std. Dev. & Min & Max & 1 & 2 & 3 & 4 & 5 & 6 & 7 & 8 & 9 & 10 \\
\hline 1 & Novelty & 1348 & -0.33 & 2.08 & -9.8 & 5.9 & & & & & & & & & & \\
\hline 2 & Competitively funded & 1385 & 0.75 & 0.43 & 0 & 1 & .08 & & & & & & & & & \\
\hline 3 & Ratio of competitive funds & 1385 & 0.59 & 0.37 & 0 & 1 & .11 & .86 & & & & & & & & \\
\hline 4 & Ln number of authors & 1399 & 1.40 & 0.61 & 0 & 5.5 & .30 & .05 & .09 & & & & & & & \\
\hline 5 & International collaboration with US & 1399 & 0.10 & 0.31 & 0 & 1 & .06 & .01 & .04 & .15 & & & & & & \\
\hline 6 & International collaboration with Western Europe & 1399 & 0.06 & 0.23 & 0 & 1 & .03 & .04 & .07 & .14 & .03 & & & & & \\
\hline 7 & International collaboration with others & 1399 & 0.10 & 0.30 & 0 & 1 & .01 & .05 & .04 & .16 & .06 & .10 & & & & \\
\hline 8 & Ln number of references & 1397 & 3.03 & 0.65 & 0 & 4.8 & .27 & .17 & .18 & .13 & .16 & .08 & .05 & & & \\
\hline 9 & Junior & 1399 & 0.21 & 0.41 & 0 & 1 & .06 & -.15 & -.13 & .09 & -.01 & -.05 & -.08 & -.03 & & \\
\hline 10 & Female & 1398 & 0.05 & 0.22 & 0 & 1 & .05 & -.06 & -.03 & .06 & .07 & -.01 & .04 & .03 & .25 & \\
\hline 11 & Peripheral university & 1399 & 0.72 & 0.45 & 0 & 1 & -.03 & -.17 & -.19 & .04 & -.05 & .01 & -.01 & -.04 & -.06 & -.04 \\
\hline
\end{tabular}

Note: Correlation with bold numbers significant at $\mathrm{p}<.05$. 
Table 3. Novelty, funding model, and status

\begin{tabular}{|c|c|c|c|c|c|c|c|c|c|}
\hline & \multicolumn{9}{|c|}{$\begin{array}{c}\text { Novelty } \\
\text { OLS }\end{array}$} \\
\hline & (1) & (2) & (3) & (4) & (5) & (6) & (7) & $(8)$ & (9) \\
\hline Competitively funded & & $\begin{array}{l}0.35 * * \\
(0.17)\end{array}$ & $\begin{array}{l}0.60 * * * \\
(0.20)\end{array}$ & $\begin{array}{l}0.40 * * \\
(0.18)\end{array}$ & $\begin{array}{l}0.89 * \\
(0.47)\end{array}$ & & & & \\
\hline Competitively funded $*$ & & & $-0.94 * * *$ & & & & & & \\
\hline Junior & & & $(0.36)$ & & & & & & \\
\hline Competitively funded $*$ & & & & $-0.95 * *$ & & & & & \\
\hline Female & & & & $(0.48)$ & & & & & \\
\hline Competitively funded $*$ & & & & & -0.64 & & & & \\
\hline Peripheral univ. & & & & & $(0.51)$ & & & & \\
\hline \multirow[t]{2}{*}{ Ratio competitive funds } & & & & & & $0.54 * * *$ & $0.72 * * *$ & $0.60 * * *$ & $0.97 * *$ \\
\hline & & & & & & $(0.18)$ & $(0.21)$ & $(0.19)$ & $(0.43)$ \\
\hline Ratio competitive funds $*$ & & & & & & & $-0.68 *$ & & \\
\hline Junior & & & & & & & $(0.38)$ & & \\
\hline Ratio competitive funds $*$ & & & & & & & & $-0.99 *$ & \\
\hline Female & & & & & & & & $(0.54)$ & \\
\hline Ratio competitive funds $*$ & & & & & & & & & -0.54 \\
\hline Peripheral univ. & & & & & & & & & $(0.48)$ \\
\hline \multirow[t]{2}{*}{ Junior } & 0.06 & 0.06 & $0.71 * *$ & 0.06 & 0.05 & 0.07 & 0.44 & 0.07 & 0.07 \\
\hline & $(0.16)$ & $(0.16)$ & $(0.32)$ & $(0.16)$ & $(0.16)$ & $(0.16)$ & $(0.30)$ & $(0.15)$ & $(0.16)$ \\
\hline \multirow[t]{2}{*}{ Female } & 0.01 & -0.29 & -0.31 & 0.28 & -0.28 & -0.30 & -0.31 & 0.21 & -0.30 \\
\hline & $(0.32)$ & $(0.24)$ & $(0.24)$ & $(0.40)$ & $(0.25)$ & $(0.24)$ & $(0.24)$ & $(0.39)$ & $(0.25)$ \\
\hline \multirow[t]{2}{*}{ Peripheral univ. } & $-0.25^{*}$ & -0.21 & -0.23 & -0.22 & 0.33 & -0.19 & -0.20 & -0.19 & 0.17 \\
\hline & $(0.14)$ & $(0.14)$ & $(0.14)$ & $(0.14)$ & $(0.49)$ & $(0.14)$ & $(0.14)$ & $(0.14)$ & $(0.39)$ \\
\hline \multirow[t]{2}{*}{ Ln authors } & $0.39 * * *$ & $0.36 * * *$ & $0.36 * * *$ & $0.37 * * *$ & $0.35 * * *$ & $0.34 * * *$ & $0.34 * * *$ & $0.35 * * *$ & $0.34 * * *$ \\
\hline & $(0.13)$ & $(0.13)$ & $(0.13)$ & $(0.13)$ & $(0.13)$ & $(0.13)$ & $(0.13)$ & $(0.13)$ & $(0.13)$ \\
\hline \multirow[t]{2}{*}{ Int. US } & 0.10 & 0.14 & 0.16 & 0.14 & 0.17 & 0.14 & 0.14 & 0.13 & 0.16 \\
\hline & $(0.22)$ & $(0.22)$ & $(0.22)$ & $(0.22)$ & $(0.23)$ & $(0.22)$ & $(0.22)$ & $(0.22)$ & $(0.23)$ \\
\hline \multirow[t]{2}{*}{ Int. Western Europe } & 0.04 & 0.03 & 0.04 & 0.03 & 0.03 & 0.01 & 0.01 & 0.00 & 0.02 \\
\hline & $(0.25)$ & $(0.24)$ & $(0.25)$ & $(0.24)$ & $(0.24)$ & $(0.24)$ & $(0.24)$ & $(0.24)$ & $(0.24)$ \\
\hline \multirow[t]{2}{*}{ Int. Other } & 0.01 & -0.13 & -0.13 & -0.13 & -0.11 & -0.12 & -0.12 & -0.12 & -0.09 \\
\hline & $(0.20)$ & $(0.17)$ & $(0.17)$ & $(0.17)$ & $(0.17)$ & $(0.18)$ & $(0.18)$ & $(0.18)$ & $(0.18)$ \\
\hline \multirow[t]{2}{*}{ Ln references } & $0.56 * * *$ & $0.51 * * *$ & $0.50 * * *$ & $0.50 * * *$ & $0.50 * * *$ & $0.49 * * *$ & $0.49 * * *$ & $0.49 * * *$ & $0.49 * * *$ \\
\hline & $(0.12)$ & $(0.12)$ & $(0.12)$ & $(0.12)$ & $(0.12)$ & $(0.12)$ & $(0.12)$ & $(0.12)$ & $(0.12)$ \\
\hline Publication year & Yes & Yes & Yes & Yes & Yes & Yes & Yes & Yes & Yes \\
\hline Field & Yes & Yes & Yes & Yes & Yes & Yes & Yes & Yes & Yes \\
\hline $\mathrm{N}$ & 1347 & 1334 & 1334 & 1334 & 1334 & 1334 & 1334 & 1334 & 1334 \\
\hline $\mathrm{R}^{2}$ & 0.30 & 0.32 & 0.33 & 0.32 & 0.32 & 0.32 & 0.33 & 0.32 & 0.32 \\
\hline
\end{tabular}

$* \mathrm{p}<.10, * * \mathrm{p}<.05, * * * \mathrm{p}<.01$. The table displays coefficients with SEs in parentheses. 

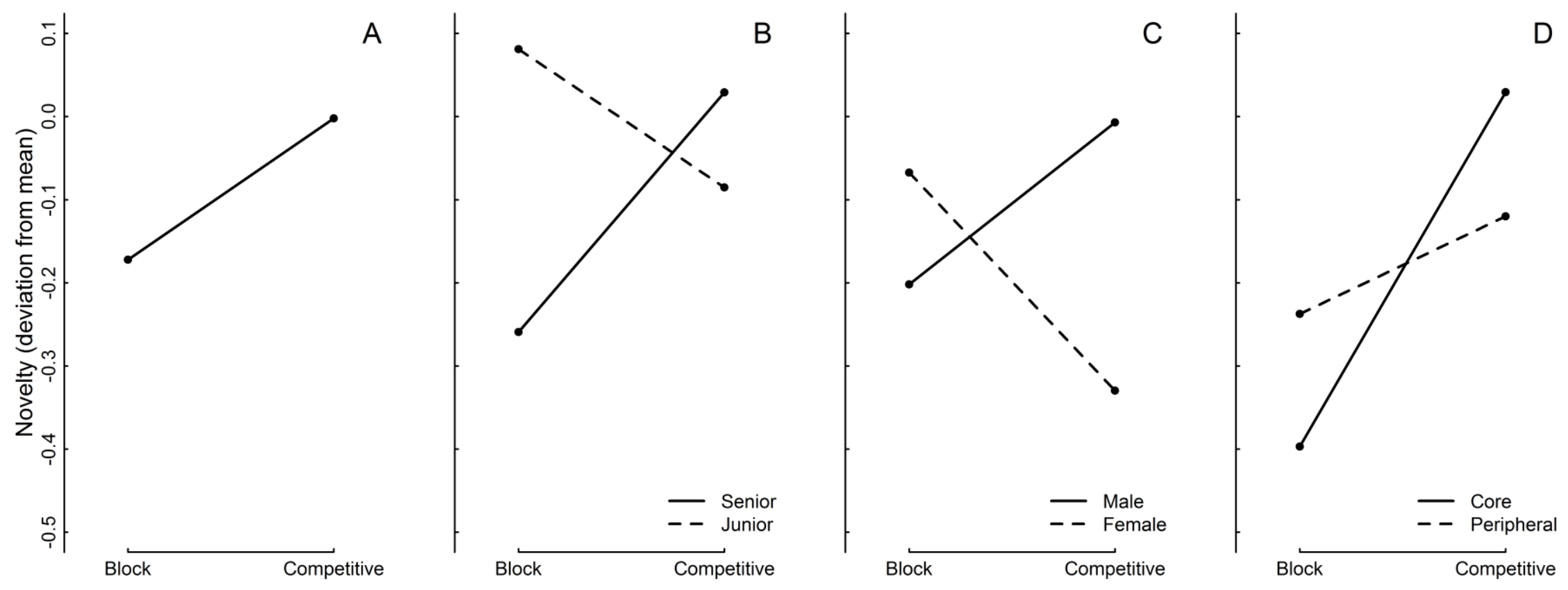

Figure 1. Novelty, funding model, and status 
Table 4. Selection vs. treatment

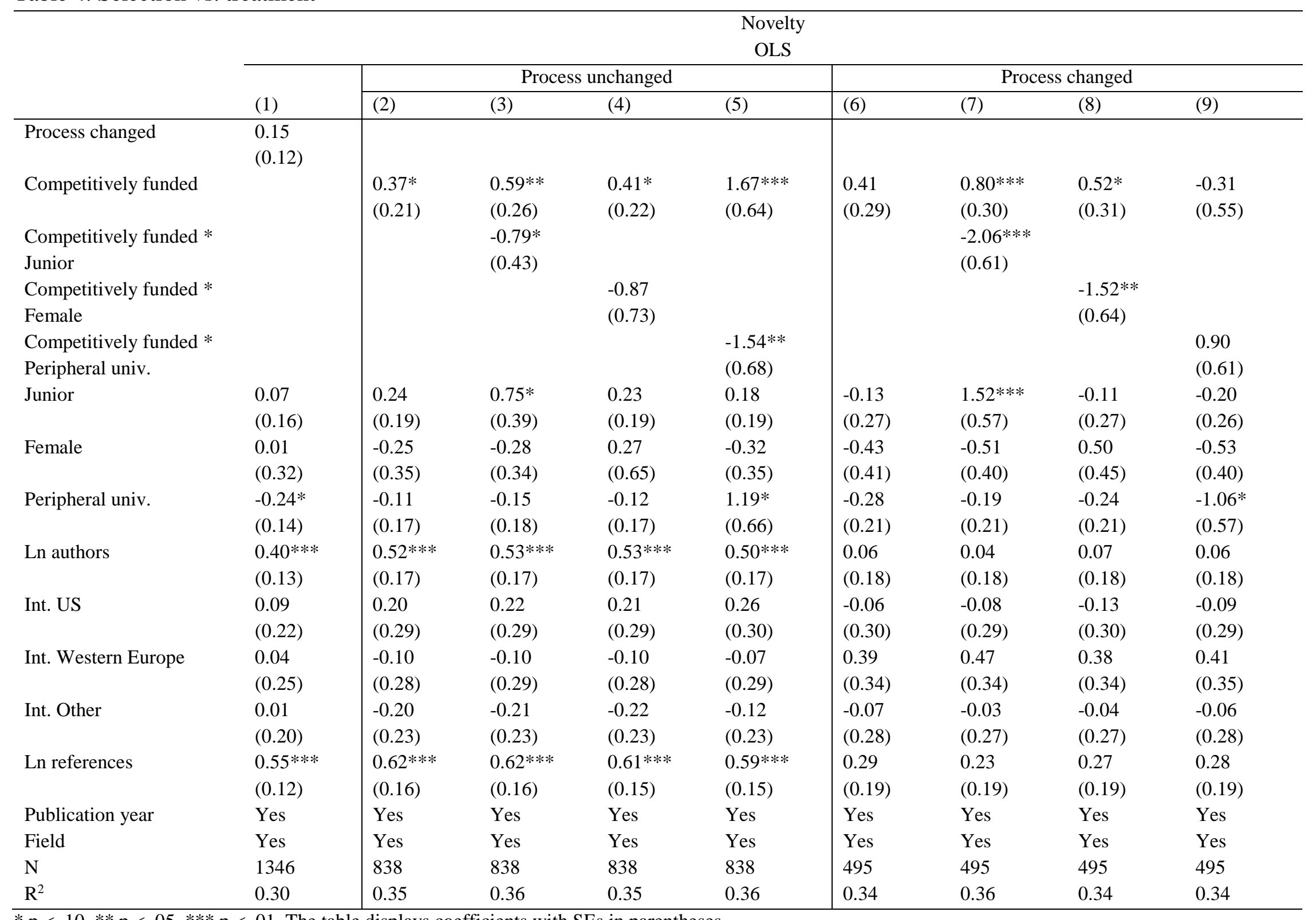

